\title{
Acute Myocarditis as Myocardial Infarction Mimic: Presentation of Case and Review of Literature
}

\section{Lea B Abucejo, Anabella A Salise-Oncog* and Julia B Maape}

Governor Celestino Gallares Memorial Hospital, Tagbilaran City, Bohol, Philippines

*Corresponding Author: Anabella A Salise-Oncog, Governor Celestino Gallares Memorial Hospital, Tagbilaran City, Bohol, Philippines.
Received: August 17, 2021.

Published: September 24, 2021

(C) All rights are reserved by Anabella A

Salise-Oncog., et al.

\section{Abstract}

Chest pain is a common symptom that results in visits to the emergency department. When it occurs, family members become worried because of the association between chest pain and cardiac disease. Although chest pain is rarely associated with serious diseases, failure to perform a timely diagnosis may result in fatalities.

This is a report on a 13-year-old obese boy who initially presented with abdominal pain and diarrhea and who subsequently complained of progressive chest pain that eventually radiated to the left arm. Initial diagnostic tests showed ST segment elevations and elevated CKMB and troponin I. He was initially managed as myocardial infarction. A 2-dimensional echocardiogram showed a low ventricular ejection fraction. Monitoring of the electrocardiogram and the cardiac enzymes showed rapid reversal of the previously seen abnormal findings, which is atypical of the course of myocardial infarction. The history, physical examination, and diagnostic findings fulfilled the criteria for acute myocarditis.

Acute myocarditis can mimic myocardial infarction and should also be considered in a patient presenting with chest pain in the Emergency Room. The clinician should be cognizant of the features outlined in this study that would help in the differential diagnoses of children presenting with chest pain. Myocarditis should be considered more than myocardial infarction in younger infants presenting with acute coronary syndrome whose ECG findings show multiple rather than single coronary artery involvement.

Keywords: Acute Myocarditis; Myocardial Infarction; ECG

\section{Introduction}

Chest pain is a common symptom that results in visits to the emergency department. When it occurs, family members become worried because of the association between chest pain and cardiac disease. Although chest pain is rarely associated with serious diseases, failure to perform a timely diagnosis may result in fatalities.

In this report we present a case of an adolescent with chest pains that turned out to be an Acute Myocarditis and a review of current literature on the condition.

\section{Case Report}

A 13-year-old boy presented to the emergency room for chest pains. He was apparently well until 2 days prior, when there was sudden onset of loose bowel movement, with watery, nonmucoid, non-bloody stools amounting to $1 / 2$ cup per episode for 4 episodes, associated with crampy periumbilical pain. His mother gave him 2 tablets of Loperamide providing relief; however, the periumbilical pain recurred 1 day prior to admission, and now associated with chest pain described as substernal, episodic, nonradiating, trig- 
gered even by minimal exertion, and relieved by rest. The chest pain was initially tolerable, with a pain score of 3-4/10, lasting less than 5 minutes, and not associated with dyspnea or palpitations; however, few hours prior to admission it became more intense (pain score: 9/10), crushing, and radiating to the left arm. Consult was sought at a nearby hospital where an electrocardiogram showed ST elevation on leads II, III, V1 to V4. Troponin I was elevated at $5.87 \mathrm{ng} / \mathrm{mL}$. He was given aspirin, clopidogrel, atorvastatin, and isosorbide dinitrate, with note of relief of symptoms. He was subsequently referred to our institution for further evaluation and management.

The review of systems did not reveal any pertinent sign or symptom. He was a fully immunized child and was previously admitted for dengue fever at 7 years old and for an unrecalled diagnosis at 9 years old. The family history revealed that the father has hypertension well-controlled by Losartan. There was no history of sudden death in both paternal and maternal sides.

On physical examination, the patient was noted to be conscious, coherent, not in respiratory distress with normal vital signs. He was also noted to be obese, with a BMI $>95^{\text {th }}$ centile for age. The cardiac rhythm was regular, the heart rate was normal for age, and there was no murmur. Peripheral perfusion was good. The rest of the PE findings were normal.

Initial work-up of the patient revealed leukocytosis with neutrophilia in the complete blood count. Both CKMB and the Troponin I were elevated at $248.6 \mathrm{u} / \mathrm{L}$ and $>10 \mathrm{ng} / \mathrm{ml}$ respectively. The chest radiograph was normal.

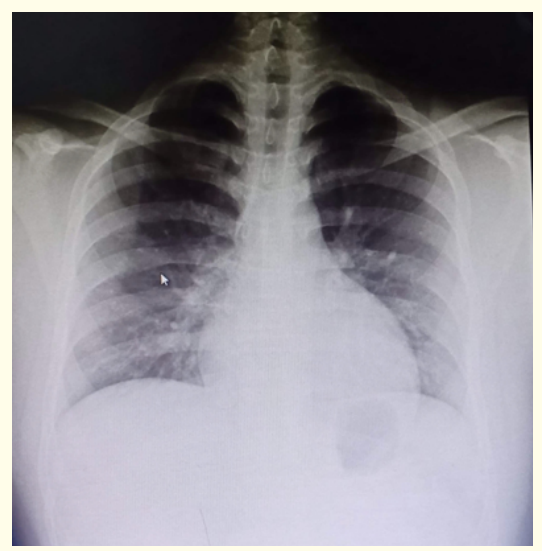

Figure 1: Chest radiograph of the patient with chest pain.
The initial electrocardiogram of the patient showed ST segment elevation at lead I, II, AVL, AVF, V2 to V6 implying of an infarction in these areas.

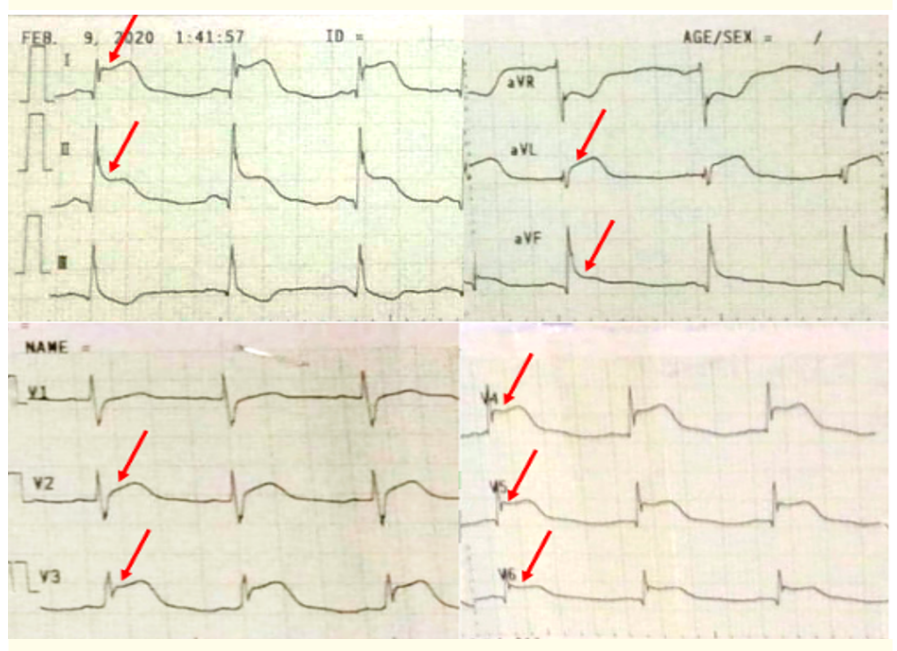

Figure 2: Initial electrocardiogram of the patient with chest pain.

\begin{tabular}{|c|c|}
\hline Test & Result \\
\hline FBC & $5.86 \mathrm{mmol} / \mathrm{L}$ \\
\hline Total cholesterol & $2.58 \mathrm{mmol} / \mathrm{L}$ \\
\hline High density lipoproteins & $0.74 \mathrm{mmol} / \mathrm{L}$ \\
\hline Low density lipoproteins & $1.47 \mathrm{mmol} / \mathrm{L}$ \\
\hline Very low density lipoproteins & $0.37 \mathrm{mmol} / \mathrm{L}$ \\
\hline Triglycerides & $0.82 \mathrm{mmol} / \mathrm{L}$ \\
\hline Sodium & $143 \mathrm{mmol} / \mathrm{L}$ \\
\hline Potassium & $3.80 \mathrm{mmol} / \mathrm{L}$ \\
\hline Ionized calcium & $1.24 \mathrm{mmol} / \mathrm{L}$ \\
\hline Ionized magnesium & $0.62 \mathrm{mmol} / \mathrm{L}$ \\
\hline Creatinine & $81.5 \mathrm{umol} / \mathrm{L}$ \\
\hline Protime & $14.9 \mathrm{~seconds}$ \\
\hline INR & 1.21 \\
\hline activity & $78.6 \%$ \\
\hline APTT & $36.8 \mathrm{~seconds}$ \\
\hline
\end{tabular}

Table 1: Other work-up of patient with chest pains.

Patient was admitted to PICU. Chest pain recurred and was relieved by sublingual nitroglycerin; a nitroglycerin patch was subsequently administered. Captopril, clopidogrel, carvedilol and atorvastatin were sequentially added under the supervision of a 
pediatric cardiologist. Intermittent recurrences of chest pain occurred but of decreasing intensity thereafter. Enoxaparin and aspirin were subsequently administered after noting normal bleeding parameters.

The repeat electrocardiogram on the second hospital day showed ST elevation at lead II, V2 and V3, and resolution of the previously seen ST elevation at leads I, II, AVL, AVF, V2 to V6.

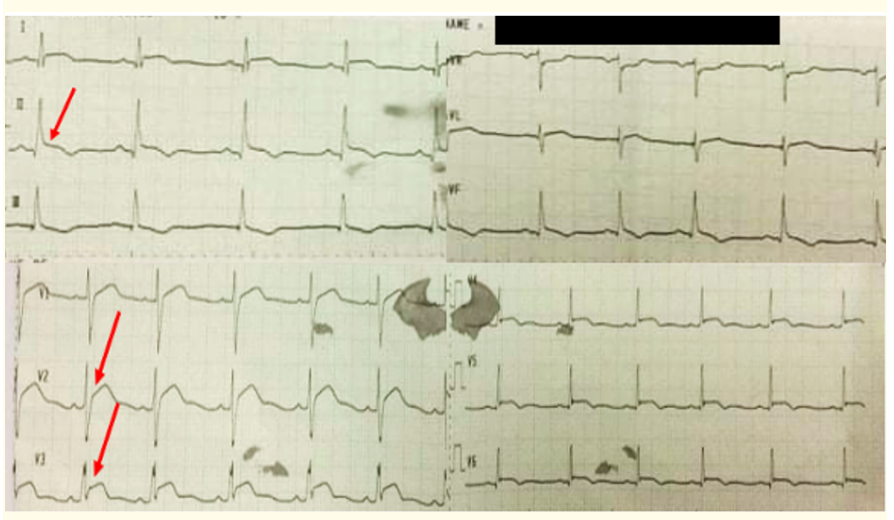

Figure 3: Repeat electrocardiogram on second hospital day.

The echocardiogram showed situs solitus, AV and VA concordance, intact interatrial and interventricular septa, normal chamber sides, poor myocardial contractility, with left ventricular ejection fraction of 46 - 48\%, normal pulmonary arterial pressure, and left-sided aortic arch. Hence, acute myocarditis was considered.

Chest pain was no longer noted starting on the fourth hospital day. Normal ST segments were also noted in the cardiac monitor starting on this day.

Repeat CKMB and Troponin I levels on the $9^{\text {th }}$ hospital day were significantly improved at $26.8 \mathrm{u} / \mathrm{L}$ (from $248.6 \mathrm{u} / \mathrm{L}$ ) and 0.46 $\mathrm{ng} / \mathrm{mL}$ (from > $10 \mathrm{ng} / \mathrm{mL}$ ) respectively. Repeat echocardiogram showed improving left ventricular ejection fraction at $66 \%$ from a previous value of $46-48 \%$.

Patient was discharged improved on the $12^{\text {th }}$ hospital day.

\section{Discussion}

After cardiac murmurs, chest pain is the second most common symptom that is referred to pediatric cardiologists [1]. In a retro- spective study on chest pain in children and adolescents conducted by Chun., et al. chest pain was most commonly noted in children 12 to 16 years age, and $58.4 \%$ of the cases were noted in males. Both characteristics were compatible with our patient since he was a 13-year-old boy. In the same study, sharp pain was the most common description of chest pain in children, and vague or undefined pain was the second most common. Squeezing pain or crushing pain, which was the one described by our patient was seen only in $17.6 \%$ of cases [2].

Idiopathic causes are the most common causes of chest pain. Respiratory problems account for $9.3 \%$ of cases, followed by musculoskeletal problems at $8.8 \%$. Cardiac causes ranked $4^{\text {th }}$ at $3.8 \%$ [2]. In a recent study Gesuete., et al. chest pain of cardiac causes is found in only $1 \%$ of cases [3]. Thus, cardiac chest pain is an uncommon but notably the most dreaded cause of chest pain because of the associated morbidity and mortality.

There are 4 broad categories of cardiac conditions that can cause chest pain, i.e. structural abnormality, coronary artery diseases, dysrhythmia, or inflammatory [4,5]. Among these uncommon causes of cardiac chest pain in children is myocardial infarction.

Myocardial infarction is a clinical condition that occurs when the coronary blood flow to the heart is reduced or interrupted. It has been defined in 2018 as the presence of acute myocardial injury detected by abnormal cardiac biomarkers in the setting of acute myocardial ischemia [6]. It is reported to be rare in children; however, literatures state that this may be underdiagnosed because of the varied etiology and atypical symptoms in children [7]. Its incidence in the United States has been reported to be 157 cases in a 13-year span, and that it is higher in adolescents 16 to 18 years old and in boys [8]. In the Russian Federation, the incidence of myocardial infarction in children is reported to be $4.48 \%$ [9]. In the Philippines, there have been only 31 cases of myocardial infarction reported in children from January 1, 2006 to April 30, 2021 based on the registry of childhood diseases of the Philippine Pediatric Society, Inc [10].

The etiologies of myocardial infarction are varied. For convenience, the mnemonics CATH IT has been used. C for congenital lesions, A for autoimmune diseases, $\mathrm{T}$ for trauma, $\mathrm{H}$ for hematologic conditions, I for infectious causes, and a second T for toxins [7]. The findings in the history and physical examination of, as well as in the diagnostic tests performed in our patient ruled out congenital 
lesions, autoimmune diseases, trauma, hematologic conditions and toxins.

Myocarditis is an inflammatory condition of the myocardium characterized by presence of inflammatory infiltrates associated with necrosis and/or degeneration of the myocardial cells; such damage is not consistent with ischemic damage from coronary artery disease [11].

The etiologies of myocarditis in children are varied and include infectious and non-infectious causes. Infectious causes include viruses, bacteria, fungi, protozoans, and even parasites. Non-infectious causes include cardiotoxins, hypersensitivity reactions, systemic disorders and radiation [12]. Viruses prevail over all etiologies, the most common of these are coxsackie B, adenovirus, parvovirus B19, Epstein-Barr virus, cytomegalovirus, and human herpes virus [13].

Myocarditis in children may be sporadic or epidemic, and comes with seasonal and geographic variation $[14,15]$. Several studies have reported the rarity of myocarditis in children. A nationwide study in Finland reported an overall incidence rate of $1.95 / 100,000$ person-years [16]. A retrospective cohort study in Taiwan reported an overall incidence rate of $0.45 / 1000$ children [17]. In a study conducted in Korea, the overall incidence rate in 2016 is $2.1 / 100,000$ children [18]. In the Philippines, the registry of childhood diseases shows that there are 4049 cases of myocarditis reported from January 1, 2006 to April 30, 2021 [19].

The incidence of myocarditis in children may even be underestimated because of subclinical cases. Moreover, the diagnosis of myocarditis may be difficult to establish because of nonspecificity of symptoms $[13,20,21]$ as well as lack of sufficiently sensitive and specific diagnostic tests of myocarditis [12]. Autopsies on children who suddenly died have shown that myocarditis can be a cause of sudden death in children. Weber., et al. reported that out of 28 histologically proven myocarditis in children 0 to 18 years, 16 (57\%) of them presented as sudden death [22]. In a Canadian study on myocarditis in infants younger than 12 months, 16 out of 21 infants with isolated myocarditis had no antecedent clinical signs or had a short clinical history of less than 24 hours [23]. Another study on myocarditis and sudden infant death syndrome reported that myocarditis may be the only explanation for the death in $10.5 \%$ of cases and may be an additional possible cause of death in $6.3 \%$ of cases [24]. Thus, current estimates on active cases of myocarditis in children may just be an underestimation of the burden of this disease.

Myocarditis has been reported to be a male-predominant disease in adults. In a nationwide multi-center registry Finnish study, myocarditis was reported to be more common in men than in women (76.61\% vs $23.39 \%, \mathrm{p}<0.0001)$ [25]. Arola., et al. conducted a study on pediatric myocarditis that also showed that it is more frequent in boys than in girls ( $77 \%$ vs $23 \%$ ), but this sex difference in incidence rate is age dependent. The incidence of myocarditis in children 0 to 5 years did not differ between sexes, but it became more frequent in boys aged 6 to 10 years (incidence rate ratio: 2.46; 95\% CI, 1.03 - 5.89; $\mathrm{p}=0.043$ ). The incidence of myocarditis even became higher in male children and adolescents aged 11 to 15 years (incidence rate ratio: 3.89; 95\% CI, 2.68 - 5.67; $\mathrm{p}<0.0001$ ) [16]. A similar pattern was also reported in Korean children with myocarditis. Kim and Cho reported that there is no significant difference in the incidence of myocarditis in children 0 to 5 years old, but there is a male preponderance in the incidence of myocarditis in adolescents aged $\geq 13$ years [18]. Our patient is notably a 13-year-old boy.

The clinical manifestations of myocarditis are variable. It may be asymptomatic or may present with myocardial infarction, or even cardiogenic shock and sudden death [13]. Nonspecific symptoms that may suggest other diagnoses may be the most prominent features at presentation. These may include anorexia, abdominal pain, vomiting, cough, tachypnea, and fever $[13,20,21]$. The symptoms are reported to vary according to age $[11,26]$. Infants may present with nonspecific symptoms like fever, listlessness, and poor feeding, or they may present with more ominous signs like apnea, episodic cyanosis, and diaphoresis. Older children may present with nonspecific respiratory or gastrointestinal complaints. Only a minority reports chest pain [26]. Our patient reported both gastrointestinal symptoms and chest pain.

Unexplained tachycardia has traditionally been considered a clue to myocarditis [27]; however, the study conducted by Durani., et al. reported that $66 \%$ of patients with myocarditis actually have normal heart rates at presentation [21]. This was the case in our patient. His heart was just 80 beats/minute on admission. 
Infrequently, myocarditis can present with signs and symptoms of myocardial infarction. This is more commonly seen in adolescents who present with chest pain, ischemic changes in the electrocardiogram, and elevated troponin levels [28]. These were seen in our patient. He was diagnosed with myocardial infarction initially.

The exact pathogenesis of myocardial infarction in myocarditis remains unclear. Hypotheses on this matter include ischemia that results from local endothelial dysfunction, coronary spasms, and in situ thrombi formation [29-31].

It is quite challenging to identify myocardial infarction from myocarditis. The table below shows the features by which myocardial infarction can be differentiated from myocarditis [32].

\begin{tabular}{|c|c|c|}
\hline Basis & Myocardial Infarction & Myocarditis \\
\hline Anamnesis & Sudden onset & $\begin{array}{l}\text { First there may be find- } \\
\text { ings of viral infection }\end{array}$ \\
\hline $\begin{array}{l}\text { Physical ex- } \\
\text { amination }\end{array}$ & $\begin{array}{l}\text { Gallop rhythm, ventricu- } \\
\text { lar arrhythmia may be } \\
\text { seen }\end{array}$ & $\begin{array}{l}\text { Sound of pericardial } \\
\text { friction } \\
\text { Gallop rhythm, and ar- } \\
\text { rhythmias may be seen }\end{array}$ \\
\hline $\begin{array}{c}\text { Electrocar- } \\
\text { diogram }\end{array}$ & $\begin{array}{l}\text { ST elevation, T wave } \\
\text { changes, pathological } \\
\text { Q wave, ventricular ar- } \\
\text { rhythmia, extended QT } \\
\text { distance }\end{array}$ & $\begin{array}{c}\text { Sinus tachycardia, low } \\
\text { voltage, PR segment de- } \\
\text { pression, ST elevation, T } \\
\text { wave changes }\end{array}$ \\
\hline $\begin{array}{c}\text { Echocardio- } \\
\text { gram }\end{array}$ & $\begin{array}{l}\text { Segmentary wall move- } \\
\text { ment abnormalities, } \\
\text { reduction in ejection } \\
\text { fraction, papillary muscle } \\
\text { rupture, left ventricle free } \\
\text { wall rupture }\end{array}$ & $\begin{array}{l}\text { Pericardial effusion, } \\
\text { reduction in ejection } \\
\text { fraction, segmentary } \\
\text { wall movement abnor- } \\
\text { malities }\end{array}$ \\
\hline $\begin{array}{c}\text { Cardiac } \\
\text { angiogram }\end{array}$ & $\begin{array}{c}\text { Coronary artery throm- } \\
\text { bosis }\end{array}$ & Normal \\
\hline $\begin{array}{l}\text { Magnetic } \\
\text { resonance }\end{array}$ & $\begin{array}{l}\text { Increased focal involve- } \\
\text { ment }\end{array}$ & $\begin{array}{c}\text { Increased signal in } \\
\text { the myocardium and } \\
\text { increased contrast } \\
\text { involvement in the myo- } \\
\text { cardium and myocardial } \\
\text { thickening }\end{array}$ \\
\hline $\begin{array}{l}\text { Telecardio- } \\
\text { gram }\end{array}$ & Normal & Cardiomegaly \\
\hline Biopsy & $\begin{array}{l}\text { Necrosis in the involved } \\
\text { area }\end{array}$ & $\begin{array}{c}\text { Necrosis and inflam- } \\
\text { matory cells in the } \\
\text { involved area }\end{array}$ \\
\hline Laboratory & $\begin{array}{c}\text { Elevated levels of tropo- } \\
\operatorname{nin}, \mathrm{CKMB}\end{array}$ & $\begin{array}{c}\text { Elevated levels of tropo- } \\
\text { nin, CKMB }\end{array}$ \\
\hline
\end{tabular}

Table 2: Myocardial infarction vs myocarditis.
As can be seen from the table above, there is a significant overlap between the features of myocardial infarction and myocarditis. It would have been best if a cardiovascular magnetic resonance or a cardiac angiogram, or a biopsy were done in order to confirm the diagnosis but our institution does not have the technology nor the expertise to perform any of these diagnostic procedures. As such, we had to rely on the history, physical examination, the elevated cardiac enzymes, the ECG and the ECHO results.

Tunuguntla., et al. in their recent article published in Pediatrics Review, stated that myocarditis is more likely than myocardial infarction in the pediatric population [33]. Moreover, Magnani and Dec wrote in their review on myocarditis that myocarditis rather than myocardial infarction should be considered in younger patients presenting with acute coronary syndrome but without coronary risk factors, who have ECG abnormalities that extend beyond the distribution of a single coronary artery, and/or a global rather than segmental left ventricular dysfunction on echocardiography [34]. A similar opinion has also been written by Ang., et al. in their case report about acute myocarditis mimicking ST-elevation myocardial infarction [35]. Our patient was a 13-year-old adolescent, who, though obese, was normotensive, and who had normal lipid profile. His electrocardiogram showed multiple rather than single coronary artery involvement. His ECG tracings were compatible with anterior, lateral, and inferior myocardial infarction. The echocardiogram showed global left ventricular ejection fraction that is low at $46-48 \%$.

Another feature in our patient that may point to myocarditis rather than myocardial infarction is the early normalization of the ST segment elevation. The ST segments returned to normal as early as on the third day of illness. In contrast, the ST segment elevation in myocardial infarction may take up to 2 weeks to normalize in inferior wall myocardial infarction, and several months in anterior wall myocardial infarction [36].

The European Society of Cardiology Working Group on Myocardial and Pericardial Diseases proposed the diagnostic criteria for clinically suspected myocarditis as seen in table 3 . The diagnosis is considered if there is $\geq 1$ clinical presentation and $\geq 1$ diagnostic criteria from the different categories in the absence of angiographically detected coronary stenosis of $\geq 50 \%$ and known pre-existing cardiovascular disease or extra-cardiac conditions that could explain the constellation of signs and symptoms. If the patient is as- 
ymptomatic, $\geq 2$ diagnostic criteria should be met. The suspicion is higher with higher number of fulfilled criteria [37].

\begin{tabular}{|c|}
\hline Clinical presentation \\
\hline Acute chest pain, pericarditic or pseudo-ischemic \\
\hline $\begin{array}{c}\text { New-onset (days up to } 3 \text { months) or worsening of dyspnea at } \\
\text { rest or exercise, and/or fatigue, with or without left and/or } \\
\text { right heart failure signs }\end{array}$ \\
\hline $\begin{array}{c}\text { Subacute/chronic ( }>3 \text { months) or worsening of dyspnea at rest } \\
\text { or exercise, and/or fatigue, with or without left and/or right } \\
\text { heart failure signs }\end{array}$ \\
\hline $\begin{array}{l}\text { Palpitation, and/or unexplained arrhythmia symptoms and/or } \\
\text { syncope, and/or aborted sudden cardiac death }\end{array}$ \\
\hline Unexplained cardiogenic shock \\
\hline Diagnostic criteria \\
\hline $\begin{array}{l}\text { 1. ECG/Holter/stress test features: Newly abnormal } 12 \text { lead ECG } \\
\text { and/or Holter and/or stress testing, any of the following: I to III } \\
\text { degree atrioventricular block, or bundle branch block, ST/T wave } \\
\text { change (ST elevation or non ST elevation, T wave inversion), si- } \\
\text { nus arrest, ventricular tachycardia or fibrillation and asystole, } \\
\text { atrial fibrillation, reduced R wave height, intraventricular con- } \\
\text { duction delay (widened QRS complex), abnormal Q waves, low } \\
\text { voltage, frequent premature beats, supraventricular tachycardia }\end{array}$ \\
\hline 2. Myocardiocytolysis markers: Elevated TnT/TnI \\
\hline $\begin{array}{l}\text { 3. Functional and structural abnormalities on cardiac imaging } \\
\text { (echo/angio/CMR): New, otherwise unexplained LV and/or RV } \\
\text { structure and function abnormality including incidental finding } \\
\text { in apparently asymptomatic subjects: regional wall motion or } \\
\text { global systolic or diastolic function abnormality, with or without } \\
\text { ventricular dilatation, with or without increased wall thickness, } \\
\text { with or without pericardial effusion, with or without endocavi- } \\
\text { tary thrombi }\end{array}$ \\
\hline $\begin{array}{l}\text { 4. Tissue characterization by CMR: Edema and/or LGE of classi- } \\
\text { cal myocarditic pattern }\end{array}$ \\
\hline
\end{tabular}

Table 3: Diagnostic criteria for clinically suspected myocarditis.

Based on these criteria, our patient had myocarditis since he had 1 clinical presentation of acute chest pain, and 3 diagnostic criteria, i.e. ST elevation, elevated TnI and left ventricular dysfunction.

\section{Conclusion}

Acute myocarditis can mimic myocardial infarction and should also be considered in a patient presenting with chest pain in the Emergency Room. The clinician should be cognizant of the features outlined in this study that would help in the differential diagnoses of children presenting with chest pain. Myocarditis should be considered more than myocardial infarction in younger infants presenting with acute coronary syndrome whose ECG findings show multiple rather than single coronary artery involvement.

\section{Bibliography}

1. Fyfe DA. "Chest pain in pediatric patients presenting to a cardiac clinic". Clinical Pediatrics 23 (1984): 321-324.

2. Chun JH., et al. "Analysis of clinical characteristics and causes of chest pain in children and adolescents". Korean Journal of Pediatrics 58.11 (2015): 440-445.

3. Gesuete V., et al. "Follow-up study of patients admitted to the pediatric emergency department for chest pain". European Journal of Pediatrics 179.2 (2020): 303-308.

4. Subspecialty Group of Cardiology, the Society of Pediatrics, Chinese Medical Association; Collaborating Group of Myocarditis, the Subspecialty Group of Cardiology, the Society of Pediatrics, Chinese Medical Association; Editorial Board, Chinese Journal of Pediatrics; Pediatric Cardiology Committee, Chinese College of Cardiovascular Physicians, Chinese Medical Doctor Association. "Diagnostic recommendation for myocarditis in children (version 2018)". Zhonghua Er Ke Za Zhi 57.2 (2019): 87-89.

5. Cava JR and Sayger PL. "Chest pain in children and adolescents". Pediatric Clinics of North America 51.6 (2004): 15531568.

6. Thygesen K., et al. "Executive Group on behalf of the Joint European Society of Cardiology (ESC)/American College of Cardiology (ACC)/American Heart Association (AHA)/World Heart Federation (WHF) Task Force for the Universal Definition of Myocardial Infarction. (2018). Fourth universal definition of myocardial infarction (2018)". Global Heart 13.4 (2018): 305338.

7. Pediatric Emergency Playbook. "MI in children" (2017).

8. Mahle WT., et al. "Myocardial infarction in adolescents". The Journal of Pediatrics 151.2 (2007): 150-154.

9. Maslennikov GP. "The incidence of myocardial ischemia in children and adolescents. Bulletin of the Orenburg State University". Orenburg, Kazakhstan 13.63 (2006): 256.

10. Philippine Pediatric Society (PPS), Inc. (n.d.). Myocardial infarction. 
11. Paul T., et al. "Myocarditis in infants and children” (2012).

12. Allan CK and Fulton DR. "Clinical manifestations and diagnosis of myocarditis in children (2021).

13. Canter CE and Simpson KE. "Diagnosis and treatment of myocarditis in children in the current era". Circulation 129.1 (2014): 115.

14. Mounts AW., et al. "A cluster of fulminant myocarditis cases in children, Baltimore, Maryland". Pediatric Cardiology 22.1 (2001): 34 .

15. Strikas RA., et al. "Temporal and geographic patterns of isolates of nonpolio enterovirus in the United States, 1970-1983". The Journal of Infectious Diseases 153.2 (1986): 346.

16. Arola A., et al. "Occurrence and features of childhood myocarditis: a nationwide study in Finland". Journal of the American Heart Association 6.11 (2017): e005306.

17. Wu MH., et al. “Contemporary postnatal incidence of acquiring acute myocarditis by age 15 years and the outcomes from a nationwide birth cohort". Pediatric Critical Care Medicine 18.12 (2017): 1153.

18. Kim J and Cho MJ. "Acute myocarditis in children: a 10-year nationwide study (2007-2016) based on the Health Insurance Review and Assessment Service Database in Korea". Korean Circulation Journal 50.11 (2020): 1013-1022.

19. Philippine Pediatric Society (PPS), Inc. (n.d.). Myocarditis.

20. Freedman SB., et al. "Pediatric myocarditis: emergency department clinical findings and diagnostic evaluation". Pediatrics 120.6 (2007): 1278-1285.

21. Durani Y., et al. "Pediatric myocarditis: presenting clinical characteristics". American Journal of Emergency Medicine 27.8 (2009): 942-947.

22. Weber MA., et al. "Clinicopathological features of paediatric deaths due to myocarditis: an autopsy series". Archives of Disease in Childhood 93.7 (2008): 594-598.

23. De Sa DJ. "Isolated myocarditis as a cause of sudden death in the first year of life". Forensic Science International 30.2-3 (1986): 113-117.

24. Råsten-Almqvist P., et al. "Myocarditis and sudden infant death syndrome”. APMIS 110.6 (2002): 469-480.
25. Kytö V., et al. "The effects of gender and age on occurrence of clinically suspected myocarditis in adulthood". Heart 99.22 (2013): 1681-1684.

26. Vashist S and Singh GK. "Acute myocarditis in children: current concepts and management". Current Treatment Options in Cardiovascular Medicine 11.5 (2009): 383-391.

27. Bohn D and Benson L. "Diagnosis and management of pediatric myocarditis". Paediatr Drugs 4.3 (2002): 171-181.

28. Simpson K., et al. "Myocarditis. In Moss and Adams' Heart Disease in Infants". Children and Adolescents, $9^{\text {th }}$ edition (2016): 1333-1330.

29. Zhang T., et al. "Acute myocarditis mimicking ST-elevation myocardial infarction: a case report and review of the literature". Experimental and Therapeutic Medicine 10.2 (2015): 459-464.

30. Cooper LTJr. "Myocarditis". The New England Journal of Medicine 360.15 (2009): 1526-1538.

31. Kühl U., et al. "Parvovirus B19 infection mimicking acute myocardial infarction". Circulation 108.8 (2003): 945-950.

32. Bilici M., et al. "Myocardial infarction in children". Intech Open (2018).

33. Tunuguntla H., et al. "Acute myocarditis and pericarditis in children". Pediatrics in Review 40.1 (2019): 14-25.

34. Magnani JW and Dec GW. "Myocarditis: current trends in diagnosis and treatment". Circulation 113.6 (2006): 876-890.

35. Ang KP., et al. "Acute myocarditis mimicking ST-elevation myocardial infarction: a diagnostic challenge for frontline clinicians". Medical Journal of Malaysia 74.6 (2019): 561-563.

36. Morris $\mathrm{F}$, et al. "ABC of clinical electrocardiography". BMJ Books (2003).

37. Caforio AL., et al. "Current state of knowledge on aetiology, diagnosis, management, and therapy of myocarditis: a position statement of the European Society of Cardiology Working Group on Myocardial and Pericardial Diseases". European Heart Journal 34.33 (2013): 2636-2648.

\section{Volume 4 Issue 10 October 2021 (C) All rights are reserved by Anabella A Salise-Oncog.,} et al. 